\title{
Urgensi Kinerja Guru SMK Via Medika Melalui Peningkatan Kompetensi Dan Motivasi Kerja
}

\author{
${ }^{1}$ Desi Prasetiyani, ${ }^{2}$ Nariah \\ Dosen Fakultas Ekonomi Universitas Pamulang \\ Email : ${ }^{1}$ Dosen02496@unpam.ac.id, ${ }^{2}$ dosen02459@unpam.ac.id
}

\begin{abstract}
ABSTRAK
Penelitian ini bertujuan untuk mengetahui Urgensi Kinerja Guru SMK Via Medika Melalui Peningkatan Kompetensi Dan Motivasi Kerja.

Metode yang digunakan adalah explanatory research dengan sampel sebanyak 24 responden. Teknik analisis menggunakan analisis statistik dengan pengujian regresi, determinasi dan uji hipotesis.

Hasil penelitian menunjukkan bahwa kompetensi berpengaruh signifikan terhadap kinerja sebesar 40,9\%, uji hipotesis diperoleh signifikansi 0,001 < 0,05. Motivasi kerja berpengaruh signifikan terhadap kinerja sebesar 29,9\%, uji hipotesis diperoleh signifikansi $0,006<0,05$. Kompetensi dan Motivasi kerja secara simultan berpengaruh signifikan terhadap kinerja sebesar $52,8 \%$, uji hipotesis diperoleh signifikansi $0,000<0,05$.
\end{abstract}

Kata Kunci: Kompetensi, Motivasi kerja, Kinerja 


\section{PENDAHULUAN}

\section{Latar Belakang Masalah}

Guru sebagai garda terdepan dalam memberikan dan berbagi ilmu pengetahuan sangatlah berjasa dalam dunia pendidikan. Mereka yang disebut pahlawan tanpa tanda jasa rela mengorbankan waktu, tenaga dan pikirannya demi mengajarkan anak didiknya yang menjadi tanggung jawabnya.

Kinerja guru dituntut untuk memberikan hasil yang baik bagi peserta didik. Harus mampu menciptakan murid yang berprestasi dilingkungan sekolah maupn di luar sekolah. Namun tuntutan dan tanggung jawab ini tidak disertai dengan imbal balik yang akan diterimanya. Kinerja guru tidaklah maksimal jika tidak didukung oleh, fasilitas, sarana dan prasarana sekolah yang memudahkan para guru dalam memberikan pelajaran. Kinerja guru yang dimaksud dalam penelitian ini adalah keluaran yang dihasilkan oleh fungsi-fungsi atau indikator suatu pekerjaan atau suatu profesi dalam waktu tertentu, Wirawan (2012:5)

Kompetensi adalah suatu kemampuan yang dilandasi oleh keterampilan dan pengetahuan yang didukung oleh sikap kerja serta penerapannya dalam melaksanakan tugas dan pekerjaan di tempat kerja yang mengacu pada persyaratan kerja yang ditetapkan, Sutrisno (2016:203)

Kompetensi seorang guru sangat berperan dalam membangun dunia pendidikan di Indonesia. Setiap guru di tuntut harus memiliki kompetensi, dan bahkan kompetensi guru juga harus dikembangkan sesuai dengan kemajuan dunia pendidikan. Kompetensi guru tidak hanya dalanm bidang ilmu pelajaran yang akan di ajarkannya, namun juga harus mampu menjadi tauladan dan pemimpin yang baik yang dapat memberikan dorongan dan motivasi kepada muridmuridnya

Motivasi guru yang dimaksud dalam penelitian ini adalah pemberian daya penggerak yang menciptakan kegairahan kerja seseorang, agar mereka mau bekarja sama, bekerja efektif, dan terintegrasi dengan segala daya upayanya untuk mencapai kepuasan, Hasibuan (2016:111). Pemberian motivasi juga penting bagi para guru, karena salah satu faktor yang mempengaruhi kinerja adalah motivasi. Kurangnya dukungan motivasi baik meteril maupun non materil akan menganggu kinerja guru dalam upaya memberikan pelajaran kepada pada peserta didiknya.

Berdasarkan latar belakang di atas, kurangnya peningkatan kompetensi berupa pelatihan dan pendidikan formal serta kurangnya sarana pemberian motivasi finansial akan mengurangi dan mengahambat kinerja guru dalam meningkatkan prestasi guru dan prestasi belajar peserta didik, oleh karena itu maka penulis tertarik untuk meneliti lebih jauh mengenai "URGENSI KINERJA GURU SMK VIA MEDIKA MELALUI PENINGKATAN KOMPETENSI DAN MOTIVASI KERJA". 


\section{Rumusan Masalah}

a. Bagaimana pengaruh kompetensi terhadap Peningkatan kinerja guru SMK Via Medika?

b. Bagaimana pengaruh motivasi terhadap Peningkatan kinerja guru SMK Via Medika?

c. Bagaimana pengaruh kompetensi dan motivasi terhadap Peningkatan kinerja guru SMK Via Medika?.

\section{Tujuan Penelitian}

a. Untuk mengetahui pengaruh kompetensi terhadap Peningkatan kinerja guru SMK Via Medika

b. Untuk mengetahui pengaruh motivasi terhadap Peningkatan kinerja guru SMK Via Medika

c. Untuk mengetahui pengaruh kompetensi dan motivasi terhadap Peningkatan kinerja guru SMK Via Medika

\section{TINJAUAN PUSTAKA}

\section{Kompetensi}

Menurut

Sutrisno (2016:203) kompetensi adalah suatu kemampuan yang dilandasi oleh keterampilan dan pengetahuan yang didukungoleh sikap kerja serta penerapannya dalam melaksanakan tugas dan pekerjaan di tempat kerja yang mengacu pada persyaratan kerja yang ditetapkan.

Menurut Gordon dalam Sutrisno (2016:204), menjelaskan beberapa aspek yang terkandung dalam konsep kompetensi sebagai berikut:
a. Pengetahuan (knowledge)
b. Pemahaman (understanding)
c. Kemampuan (skill)
d. Nilai (value)
e. Sikap (attitude)

f. Minat (interest).

\section{Motivasi Kerja}

Menurut

Hasibuan (2016:111) mengemukakan motivasi adalah pemberian daya penggerak yang menciptakan kegairahan kerja seseorang, agar mereka mau bekarja sama, bekerja efektif, dan terintegrasi dengan segala daya upayanya untuk mencapai kepuasan.

Salah satu upaya yang digunakan untuk pengukuran motivasi, yaitu teori yang dikemukakan oleh Maslow yang menjadi Indikator motivasi menurut Hasibuan (2016:154) adalah sebagai berikut :
a. Kebutuhan Psikologi (physiological needs)
b. Keamanan dan keselamatan (safety and security needs)
c. Kebutuhan sosial (affiliation or acceptance needs)
d. Penghargaan dan pengakuan (esteem or status needs)
e. Aktualisasi diri (self actualization)

\section{Kinerja}

Menurut Wirawan (2012:5) kinerja adalah keluaran yang dihasilkan oleh fungsi-fungsi atau indikator suatu pekerjaan atau suatu profesi dalam waktu tertentu. Indikator kinerja menurut Wirawan (2012:166) adalah :
a. Keterampilan kerja
b. Kualitas
c. Tanggung jawab
d. Disiplin
e. Prakarsa
f. Kerja sama
g. Kuantitas) 


\section{METODE PENELITIAN}

\section{Populasi}

Populasi dalam penelitian ini berjumlah 24 responden SMK Via Medika Ciputat Tangerang

\section{Sampel}
Jumlah
sampel dalam penelitian ini peneliti menggunakan teknik sampling jenuh atau sensus di mana semua anggota populasi yang berjumlah 24 dijadikan sampel/responden.

\section{Jenis Penelitian}

Jenis penelitian yang dipakai adalah asosiatif, dimana tujuannya adalah untuk mengetahui mencari keterhubungan antara.

\section{Metode Analisis Data}

Dalam menganalisis data digunakan uji instrumen, uji asumsi klasik, regresi, koefisien determinasi dan uji hipotesis.

\section{HASIL PENELITIAN}

\section{Analisis Deskriptif}

Pada pengujian ini digunakan untuk mengetahui baik tidaknya instrumen dari masingmasing variabel. Adapun hasilnya sebagai berikut:

Tabel 1. Hasil Analisis Descriptive Statistics

\section{Descriptive Statistics}

\begin{tabular}{lr|r|r|r|r|r} 
& N & Minimum & Maximum & Sum & Mean & Std. Deviation \\
\hline Kompetensi (X1) & 24 & 39 & 58 & 1162 & 48,42 & 4,053 \\
\hline Motivasi (X2) & 24 & 30 & 44 & 858 & 35,75 & 3,981 \\
\hline Kinerja (Y) & 24 & 51 & 66 & 1371 & 57,13 & 3,971 \\
\hline Valid N (listwise) & 24 & & & & & \\
\hline
\end{tabular}

Skor total instrument Kompetensi $\left(\mathrm{X}_{1}\right)$ sebesar 1162 dan rata-rata skor $4,03 \quad(48,42: 12$ jumlah instrument) masuk kedalam interval 3,41 - 4,20 dengan kategori Baik, dengan demikian dapat disimpulkan bahwa, peningkatan Kompetensi guru SMK Via Medika saat ini sudah Baik.

Skor total instrument Kompetensi $\left(\mathrm{X}_{2}\right)$ sebesar 858 dan rata-rata skor $3,58 \quad(35,75: 10$ jumlah instrument) masuk kedalam interval 3,41 - 4,20 dengan kategori Baik, dengan demikian dapat disimpulkan bahwa, Motivasi guru SMK Via Medika saat ini sudah Baik.

Skor total instrument Kinerja (Y) sebesar 1371 dan rata-rata skor $4,08 \quad(57,13 \quad: \quad 14$ jumlah instrument) masuk kedalam interval 3,41 - 4,20 dengan kategori Baik, dengan demikian dapat disimpulkan bahwa, Peningkatan Kinerja guru SMK Via Medika saat ini sudah Baik.

\section{Analisis Verifikatif.}

Pada analisis ini dimaksudkan untuk mengetahui pengaruh variabel independen terhadap variabel dependen.

\section{a. Analisis Regresi Linier Berganda}

Regresi linear adalah untuk meramalkan atau memprediksi besaran nilai variabel terikat yang dipengaruhi oleh variabel bebas. Adapun hasil pengujiannya adalah: 
Tabel 2. Output Regresi Berganda Kompetensi ( $\left.\mathrm{X}_{1}\right)$ dan Motivasi $\left(\mathrm{X}_{2}\right)$

Terhadap Kinerja ( $Y$ ) Coefficients $^{a}$

\begin{tabular}{|c|c|c|c|c|c|c|}
\hline \multirow{2}{*}{\multicolumn{2}{|c|}{ Model }} & \multicolumn{2}{|c|}{$\begin{array}{l}\text { Unstandardized } \\
\text { Coefficients }\end{array}$} & \multirow{2}{*}{$\begin{array}{c}\text { Standardized } \\
\text { Coefficients } \\
\text { Beta }\end{array}$} & \multirow[b]{2}{*}{$t$} & \multirow[b]{2}{*}{ Sig. } \\
\hline & & $\mathrm{B}$ & Std. Error & & & \\
\hline \multirow[t]{3}{*}{1} & (Constant) & 19,750 & 7,760 & & 2,545 &, 019 \\
\hline & Kompetensi (X1) & ,501 & 157 &, 511 & 3,195 & ,004 \\
\hline & Motivasi (X2) & ,367 & 160 & ,368 & 2,303 & ,032 \\
\hline
\end{tabular}

a. Dependent Variable: Kinerja (Y)

Berdasarkan tabel Coefisientsa di atas diketahui persamaan adalah $\mathrm{Y}=19,750+$ $0,501(\mathrm{X} 1)+0,367(\mathrm{X} 2)$ persamaan ini dapat disimpulkan bahwa, terdapat arah pengaruh positif Kompetensi $(X \neg 1)$ dan Motivasi $(\mathrm{X} \neg 2)$ terhadap Kinerja (Y). Dari persamaan tersebut dijelaskan sebagai berikut:

a) Constant $=19,750$ disimpulkan bahwa, nilai variabel Kinerja (Y) sebesar 19,750 satuan dengan asumsi variabel Kompetensi $\left(\mathrm{X}_{1}\right)$ dan Motivasi $\left(\mathrm{X}_{2}\right)$ bernilai tetap atau tidak berubah.

b) Koefisien regresi b1 $=0,501$ disimpulkan apabila Kompetensi $\left(\mathrm{X}_{1}\right)$ meningkat satu-satuan, maka akan meningkatkan Kinerja (Y) sebesar 0,501 satuan.

c) Koefisien regresi b2 $=0,367$ disimpulkan apabila Motivasi $\left(\mathrm{X}_{2}\right)$ meningkat satu-satuan, maka akan meningkatkan Kinerja (Y) sebesar 0,367 satuan.

b. Analisis Koefisien Korelasi

Koefisien determinasi (KD) angka yang menyatakan atau digunakan untuk mengetahui kontribusi atau sumbangan yang diberikan oleh sebuah variabel atau lebih $\mathrm{X}$ (bebas) terhadap Y (terikat). Koefiien determinasi dilambangkan dengan R Square $\left(\mathrm{r}^{2}\right)$ :

Tabel 3. Output Determinasi Kompetensi $\left(X_{1}\right)$ Terhadap Kinerja (Y)

Model Summary

\begin{tabular}{|c|c|c|c|c|}
\hline Model & $\mathrm{R}$ & R Square & $\begin{array}{l}\text { Adjusted R } \\
\text { Square }\end{array}$ & $\begin{array}{c}\text { Std. Error of the } \\
\text { Estimate }\end{array}$ \\
\hline 1 & $640^{a}$ & 409 & ,382 & 3,121 \\
\hline
\end{tabular}

Berdasarkan tabel Model Summary di atas diketahui $\mathrm{R}$ Square $\quad 0,409 \quad$ maka disimpulkan kontribusi pengaruh Kompetensi $(\mathrm{X} \neg 1)$

Tabel 4. Output Determinasi Motivasi $\left(X_{2}\right)$ Terhadap Kinerja (Y) Model Summary

\begin{tabular}{ll|r|r|r} 
Model & $\mathrm{R}$ & R Square & \multicolumn{1}{c|}{$\begin{array}{c}\text { Adjusted R } \\
\text { Square }\end{array}$} & $\begin{array}{c}\text { Std. Error of the } \\
\text { Estimate }\end{array}$ \\
\hline 1 &, $547^{\mathrm{a}}$ &, 299 &, 267 & 3,400 \\
\hline
\end{tabular}


Berdasarkan tabel Model Summary di atas diketahui $\mathrm{R}$ Square $\quad 0,299 \quad$ maka disimpulkan kontribusi pengaruh Motivasi $\left(\mathrm{X}_{2}\right)$ Terhadap Kinerja (Y) sebesar
$29,9 \%$ dan sisanya $71,1 \%$ dipengaruhi faktor lain di luar model.

Tabel 5. Output Determinasi Kompetensi $\left(X_{1}\right)$ dan Motivasi $\left(X_{2}\right)$ Terhadap Kinerja (Y) Model Summary ${ }^{b}$

\begin{tabular}{|c|c|c|c|c|}
\hline \multicolumn{5}{|c|}{. viver summany } \\
\hline Model & $\mathrm{R}$ & R Square & $\begin{array}{l}\text { Adjusted R } \\
\text { Square }\end{array}$ & $\begin{array}{l}\text { Std. Error of the } \\
\text { Estimate }\end{array}$ \\
\hline 1 &, $727^{a}$ & ,528 & ,483 & 2,854 \\
\hline
\end{tabular}

Berdasarkan tabel Model Summary $^{b}$ di atas diketahui $\mathrm{R}$ Square $\quad 0,528 \quad$ maka disimpulkan kontribusi pengaruh Kompetensi $\left(\mathrm{X}_{1}\right)$ dan Motivasi $\left(\mathrm{X}_{2}\right)$ Terhadap Kinerja (Y) sebesar $52,8 \%$ dan sisanya $47,2 \%$ dipengaruhi faktor lain di luar model.

\section{c. Uji Hipotesis}

Uji hipotesis Parsial (Uji t)

Untuk mengetahui pengaruh secara parsial, pengujian hipotesis dilakukan dengan uji t-test. Sedangkan unutk mengetahui pengaruh secara simultan digunakan UJi F.

Pengujian parsial dilakukan melalui uji $t$ dengan membandingkan thitung (th) dengan ttabel (tt) pada $\alpha 0,05$. Apabila hasil perhitungan menunjukkan:
a. Jika $t_{\text {hitung }}>t_{\text {tabel }} 2,074$ atau nilai sig $<0,05$ maka Ho ditolak dan $\mathrm{Ha}$
b. Jika $t_{\text {hitung }} \leq \mathrm{t}_{\text {tabel }} 2,074$ atau nilai sig $\geq 0,05$ maka Ho diterima dan Ha ditolak.

Tabel 9. Output Uji t (Parsial) Kompetensi ( $\left.\mathbf{X}_{1}\right)$ Terhadap Kinerja (Y) Coefficients $^{\mathbf{a}}$

\begin{tabular}{|c|c|c|c|c|c|c|}
\hline \multirow{2}{*}{\multicolumn{2}{|c|}{ Model }} & \multicolumn{2}{|c|}{$\begin{array}{l}\text { Unstandardized } \\
\text { Coefficients }\end{array}$} & \multirow{2}{*}{$\begin{array}{c}\text { Standardized } \\
\text { Coefficients } \\
\text { Beta }\end{array}$} & \multirow[b]{2}{*}{$\mathrm{t}$} & \multirow[b]{2}{*}{ Sig. } \\
\hline & & B & Std. Error & & & \\
\hline \multirow[t]{2}{*}{1} & (Constant) & 26,787 & 7,800 & & 3,434 &, 002 \\
\hline & Kompetensi (X1) & ,627 & ,161 & ,640 & 3,903 & 001 \\
\hline
\end{tabular}

Berdasarkan tabel Coefisients $^{a}$ di atas diketahui nilai thitung $3,903>\mathrm{t}_{\text {tabel }} 2,074$ atau nilai sig $0,001<0,05$ maka
$\mathrm{Ho}_{1}$ ditolak dan $\mathrm{Ha}_{1}$ maka dapat disimpulkan Terdapat pengaruh Kompetensi $\left(\mathrm{X}_{1}\right)$ terhadap 
Kinerja Guru (Y) pada SMK

Via Medika Tangerang.

Tabel 10. Output Uji t (Parsial) Motivasi ( $\left.\mathbf{X}_{2}\right)$ Terhadap Kinerja (Y) Coefficients $^{\mathrm{a}}$

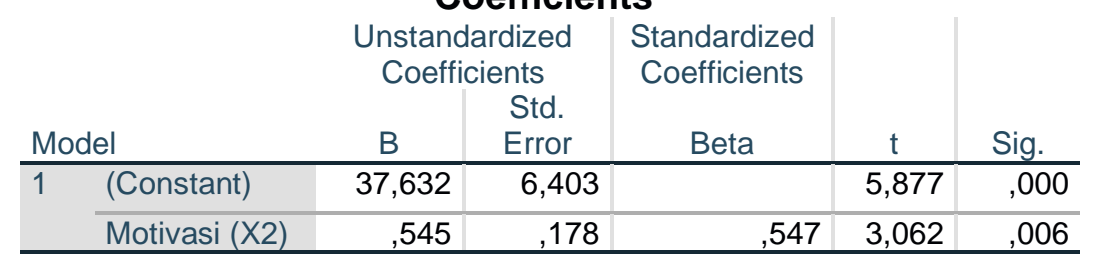

a. Dependent Variable: Kinerja (Y)

Berdasarkan tabel Coefisients $^{a}$ di atas diketahui nilai thitung $3,062>\mathrm{t}_{\text {tabel }} 2,074$ atau nilai sig $0,006<0,05$ maka $\mathrm{Ho}_{2}$ ditolak dan $\mathrm{Ha}_{2}$ maka dapat disimpulkan Terdapat pengaruh Motivasi $\left(\mathrm{X}_{2}\right)$ terhadap Kinerja Guru (Y) pada SMK Via Medika Tangerang..

\section{Uji Hipotesis Simultan (Uji F)}

Untuk mengetahui pengaruh variabel bebas $\left(\mathrm{X}_{1}\right.$ dan $\left.\mathrm{X}_{2}\right)$ secara simultan (bersamasama) terhadap variabel (Y) digunakan uji F. Kaidah pengujian signifikasi :

1) Jika $F_{\text {hitung }} \leq F_{\text {tabel }} 3,467$ atau nilai sig $\geq 0,05$, maka Ho diterima dan Ha ditolak (tidak signifikan).

2) Jika $F_{\text {hitung }}>F_{\text {tabel }} 3,467$ atau nilai sig $<0,05$, maka Ho ditolak dan $\mathrm{Ha}$ diterima (signifikan).

Tabel 11. Output Uji F (Simultan) Kompetensi $\left(X_{1}\right)$ dan Motivasi $\left(X_{2}\right)$

\section{Terhadap Kinerja (Y)}

ANOVA $^{a}$

\begin{tabular}{llr|r|r|r|r}
\multicolumn{1}{l}{ Model } & Sum of Squares & df & Mean Square & F & \multicolumn{1}{c}{ Sig. } \\
\hline 1 & Regression & 191,554 & 2 & 95,777 & 11,757 &, $000^{\mathrm{b}}$ \\
\cline { 2 - 7 } & Residual & 171,071 & 21 & 8,146 & & \\
\cline { 2 - 7 } & Total & 362,625 & 23 & & & \\
\hline
\end{tabular}

a. Dependent Variable: Kinerja $(\mathrm{Y})$

b. Predictors: (Constant), Motivasi (X2), Kompetensi (X1)

Berdasarkan tabel ANOVA di atas diketahui nilai $F_{\text {hitung }} 11,757>\mathrm{F}_{\text {tabel }} 3,467$ atau nilai sig $0,000<0,05$ maka $\mathrm{Ho}_{3}$ ditolak dan $\mathrm{Ha}_{3}$ maka dapat disimpulkan Terdapat pengaruh secara simultan Kompetensi $\left(\mathrm{X}_{1}\right)$ dan Motivasi $\left(\mathrm{X}_{2}\right)$ terhadap Kinerja Guru (Y) pada SMK Via Medika Tangerang.
PEMBAHASAN

PENELITIAN

1. Pengaruh Terhadap Kinerja

Terdapat pengaruh Kompetensi $\left(\mathrm{X}_{1}\right)$ terhadap Kinerja Guru (Y) pada SMK Via Medika Tangerang hal ini dibuktikan dengan persamaan regresi $\mathrm{Y}=$ $26,787+0,627\left(\mathrm{X}_{1}\right)$. Kontribusi pengaruh Kompetensi $\left(\mathrm{X}_{1}\right)$ 
Terhadap Kinerja (Y) sebesar $40,9 \%$ dan sisanya $59,1 \%$ dipengaruhi faktor lain. Uji hipotesis parsial menunukkan nilai $t_{\text {hitung }} 3,903>\mathrm{t}_{\text {tabel }} 2,074$ atau nilai sig $0,001<0,05$

\section{Pengaruh Motivasi Kerja} Terhadap Kinerja

Terdapat pengaruh Motivasi $\left(\mathrm{X}_{2}\right)$ terhadap Kinerja Guru (Y) pada SMK Via Medika Tangerang hal ini dibuktikan dengan persamaan regresi $\mathrm{Y}=37,632+$ $0,545\left(\mathrm{X}_{2}\right)$. Kontribusi pengaruh Motivasi $\left(\mathrm{X}_{2}\right)$ Terhadap Kinerja (Y) sebesar $29,9 \%$ dan sisanya $71,1 \%$ dipengaruhi faktor lain. Uji hipotesis parsial menunukkan nilai $t_{\text {hitung }} 3,062>t_{\text {tabel }} 2,074$ atau nilai sig $0,006<0,05$.

3. Pengaruh Kompetensi dan Motivasi Kerja Terhadap Kinerja

Terdapat pengaruh secara simultan Kompetensi $\left(\mathrm{X}_{1}\right)$ dan Motivasi $\left(\mathrm{X}_{2}\right)$ terhadap Kinerja Guru (Y) pada SMK Via Medika Tangerang hal ini dibuktikan dengan persamaan regresi $\mathrm{Y}=$ $19,750+0,501\left(\mathrm{X}_{1}\right)+0,367\left(\mathrm{X}_{2}\right)$. Kontribusi pengaruh Kompetensi $\left(\mathrm{X}_{1}\right)$ dan Motivasi $\left(\mathrm{X}_{2}\right)$ Terhadap Kinerja (Y) sebesar 52,8\% dan sisanya $47,2 \%$ dipengaruhi faktor lain. Uji hipotesis simultan menunjukkan nilai $F_{\text {hitung }} 11,757>$ $F_{\text {tabel }} 3,467$ atau nilai sig $0,000<$ 0,05 .

\section{KESIMPULAN DAN SARAN}

\section{A. Kesimpulan}

1. Terdapat pengaruh Kompetensi $\left(\mathrm{X}_{1}\right)$ terhadap Kinerja Guru (Y) pada SMK Via Medika Tangerang hal ini dibuktikan dengan persamaan regresi $\mathrm{Y}=26,787+$ 0,627 $\left(\mathrm{X}_{1}\right) . \quad$ Kontribusi pengaruh Kompetensi $\left(\mathrm{X}_{1}\right)$ Terhadap Kinerja (Y) sebesar $40,9 \%$ dan sisanya $59,1 \%$ dipengaruhi faktor lain. Uji hipotesis parsial menunukkan nilai $t_{\text {hitung }} 3,903>\mathrm{t}_{\text {tabel }} 2,074$ atau nilai sig $0,001<0,05$

2. ) terhadap Kinerja Guru (Y) pada SMK Via Medika Tangerang hal ini dibuktikan dengan persamaan regresi $\mathrm{Y}=$ $37,632+0,545\left(X_{2}\right)$. Kontribusi pengaruh Motivasi $\left(\mathrm{X}_{2}\right)$ Terhadap Kinerja (Y) sebesar $29,9 \%$ dan sisanya $71,1 \%$ dipengaruhi faktor lain. Uji hipotesis parsial menunukkan nilai $t_{\text {hitung }} 3,062>t_{\text {tabel }} 2,074$ atau nilai sig $0,006<0,05$.

3. Terdapat pengaruh secara simultan Kompetensi $\left(\mathrm{X}_{1}\right)$ dan Motivasi $\left(\mathrm{X}_{2}\right)$ terhadap Kinerja Guru (Y) pada SMK Via Medika Tangerang hal ini dibuktikan dengan persamaan regresi $\mathrm{Y}=19,750+0,501\left(\mathrm{X}_{1}\right)$ $+\quad 0,367\left(\mathrm{X}_{2}\right)$. Kontribusi pengaruh Kompetensi $\left(\mathrm{X}_{1}\right)$ dan Motivasi $\left(\mathrm{X}_{2}\right) \quad$ Terhadap Kinerja (Y) sebesar 52,8\% dan sisanya $47,2 \%$ dipengaruhi faktor lain. Uji hipotesis simultan menunjukkan nilai $\mathrm{F}_{\text {hitung }} 11,757>\mathrm{F}_{\text {tabel }} 3,467$ atau nilai sig $0,000<0,05$

\section{B. Saran}

1. Skor terendah pada instrument ini yaitu pada instrument no 6 dengan rata-rata skor 3,58 meskipun skor ini masuk kedalam kategori Baik namun juga terendah dibanding skor instrument lainnya, maka dari 
itu disarankan agar guru lebih menguasai lebih dari satu bidang ilmu pengetahuan

2. Skor terendah pada instrument ini yaitu pada instrument no 2 dengan rata-rata skor 2,75 dan no 1 dengan rata-rata skor 2,79 , maka dari itu disarankan agar pihak sekolah lebih meningkatkan secara materi khususnya gaji dan upah guru agar kebutuhan guru terpenuhi selama dan daapat mampu memenuhi taraf hidup guru dan keluarganya

3. Skor terendah pada instrument ini yaitu pada instrument no 13 dengan rata-rata skor 3,75 meskipun skor ini masuk kedalam kategori Baik namun juga terendah dibanding skor instrument lainnya, maka dari itu disarankan agar pihak sekolah lebih menyesuaikan jumlah jam pengajaran yang diberikan sesuai dengan kemampuan guru.

\section{DAFTAR PUSTAKA}

Akmal hawi, 2013. Kompetensi Guru Pendidikan Agama Islam, Jakarta; Rajawali Pers

Arikunto, S. 2016. Prosedur Penelitian Suatu Pendekatan Praktik. Jakarta: Rineka Cipta

Astrid Setianing Hartanti dan Tjutju Yuniarsih (2018). Pengaruh kompetensi profesional guru dan motivasi kerja terhadap kinerja guru di sekolah menengah kejuruan. JURNAL PENDIDIKAN MANAJEMEN PERKANTORAN

Vol.3No.1,Januari2018,Hal.1927
D Sunarsi. (2020). Kepemimpinan Bisnis Strategik. Kota Serang: Desanta Muliavisitama

Hasibuan. S. P Malayu. 2016. Manajemen Sumber Daya Manusia. Jakarta: Penerbit : Bumi Aksara.

Keputusan Menteri Pendidikan Nasional Republik Indonesia No 045/U/2002

Mangkunegara, Anwar Prabu. (2013) Manajemen Sumber Daya Manusia Untuk Perusahaan. Bandung: Remaja Rosdakarya Muhammad Hasan (2017). Pengaruh Kompetensi Profesional Guru Terhadap Kinerja Guru Ekonomi Sekolah Menengah Atas Negeri Di Kabupaten Gowa. Jurnal Economix Volume 5 Nomor 2 Desember 2017

Ratika Sari Dewi, Taufani C. Kurniaitun dan Abubakar (2018). Kemampuan Profesional Guru Dan Motivasi Kerja Terhadap Kinerja Mengajar Guru Sekolah Dasar. urnal Administrasi Pendidikan Vol.XXV No.1 April 2018

Sobarna, A., Hambali, S., Sutiswo, S., \& Sunarsi, D. (2020). The influence learning used $\mathrm{ABC}$ run exercise on the sprint capabilities. Jurnal Konseling dan Pendidikan, 8(2), 67-71.

Sugiyono, 2010, Metode Penelitian Bisnis, Bandung, Alfabeta

Sunarsi, D. (2018). Buku Ajar: Seminar Perencanaan Sumber Daya Manusia. Tangerang Selatan: Asmoro Mediatama 
Sunarsi, D. (2018). Pengembangan Sumber Daya Manusia Strategik \& Karakterisrik Sistem Pendukungnya : Sebuah Tinjauan. Jurnal Ilmiah MEA (Manajemen, Ekonomi, \& Akuntansi), 2(3), $178-194$.

Sunarsi, D. (2019). Seminar Sumber Daya Manusia. Tangerang Selatan: Unpam Press

Sutrisno. Edy. 2016. Manajemen Personalia Dan Manajemen Sumber Daya Manusia. Jakarta: Prenada Media Group.

Undang-Undang Republik Indonesia Nomor 14 Tahun 2005

Winardi. 2011. Kepemimpinan dalam Manajemen, Jakarta: Rineka Cipta.

Wirawan. 2012. Evaluasi Kinerja Sumber Daya Manusia: Teori. Aplikasi dan Penelitian. Jakarta: Salemba Empat.
Yenny (2018). Pengaruh Kompetensi, Motivasi Dan Disiplin Kerja Terhadap Kinerja Guru Pada Yayasan Pendidikan Imanuel Palu. Jurnal Katalogis, Volume 6 Nomor 2 Februari 2018 hlm 98-105

Yohanes Sukamto, Pardjono (2016). Pengaruh Kompetensi Guru, Komitmen Kerja Dan Motivasi Kerja Terhadap Kinerja Guru Smp Andalan Di Sleman. JURNAL PENELITIAN ILMU PENDIDIKAN, Volume 9, Nomor 2, September 2016

Yuangga, K. D., \& Sunarsi, D. (2018). The Influence of Procrastination and Low Time Management on Student Self Efficacy (at MA Soebono Mantofani). PINISI Discretion Review, 2(1), 85-92. 